Www.jmscr.igmpublication.org

Impact Factor (SJIF): 6.379

Index Copernicus Value: 79.54

ISSN (e)-2347-176x ISSN (p) 2455-0450

crossrefDOI: https://dx.doi.org/10.18535/jmscr/v6i12.107

Journal Of Medical Science And Clinical Research

IGM Publication

An Official Publication of IGM Publication

\title{
Preferred Audience of HIV Status Disclosure and Reasons among HIV Positive Individuals in Cross River State
}

Authors

\section{Iwasam Elemi Agbor ${ }^{1}$, Nnette Okon Ekpenyong ${ }^{2}$, Ekpe EL $^{3}$}

${ }^{1,2}$ Senior Consultant, Department of Community Medicine, Faculty of Medicine and Dentistry, University of Calabar, Calabar, Cross River State, Nigeria

${ }^{3}$ Senior Consultant, Dept of Chemical Pathology, Faculty of Medicine and Dentistry, University of Calabar, Calabar, Cross River State, Nigeria

\begin{abstract}
HIVIAIDS remains a global public health problem. HIV, the virus that causes AIDS, "acquired immunodeficiency syndrome" has become one of the world's most serious health and development challenges. A critical element of reducing HIV transmission risk is disclosure of HIV sero status by HIV positive individuals. Disclosure is recommended during post-test counseling since it supports risk reduction behaviours and facilitates access to prevention, care and treatment services for people living with HIV/AIDS (PLWHA), their partner(s) or infant $(s) .^{6}$

This study aimed to determine preferred audience of HIV status disclosure among HIV positive individuals, compare preferred audience of HIV status disclosure among HIV positive individuals and to assess and compare reasons for HIV status disclosure to preferred audience among HIV positive individuals in urban and rural areas of Cross River State.

Material and Method: The study was cross-sectional descriptive among 160 HIV positive individuals each from urban and rural areas of Cross River State selected by multi-stage sampling technique. A pre-tested interviewer-administered questionnaire was used to collect information on sociodemographic, HIV status disclosure and audience of disclosure.

Results: The highest number of married/cohabiting respondents reported they disclosed to their spouse (31.1\%. This was higher in the urban compared with rural (36.2\% versus $25.0 \%)$. This was followed by disclosure to biological relative also higher in urban than rural (31.3\% versus $23.6 \%)$. More respondents reported disclosure to their mother in rural than urban (12.5\% versus $7.7 \%)$. Audience of disclosure to whom the least number of respondents disclosed their HIV status to in both study area was work colleague $(2.0 \%)$ by urban and $(0.5 \%)$ by rural respondents. Reasons for HIV status disclosure in the urban area were to get encouragement, advice or to encourage others, to help their spouse/sex partner go for test. Among the rural respondents, the highest reason reported was to enable them take their HAART freely.
\end{abstract}

\section{Introduction}

\section{Background information}

HIV/AIDS remains a global public health problem. HIV, the virus that causes AIDS, "acquired immunodeficiency syndrome" has become one of the world's most serious health and development challenges. The first cases were reported in 1981 and today there are 
approximately 35 million people currently living with HIV and tens of millions of people have died of AIDS-related causes since the beginning of the epidemic. There were about 2.1 million new infections in 2013 or about 6,000 new infections per day. ${ }^{1}$ Most of the new infections are transmitted heterosexually, although risk factor varies. HIV/AIDs is ravaging the sub-Saharan Africa, with more than $60 \%$ of all HIV infections in the world occurring in this region. ${ }^{1}$ Forty-Seven percent $(47 \%)$ of HIV-positive men and $21 \%$ of HIV-positive women are said to be sexually active before initiating ARV treatment with $45 \%$ of these men and women who are HIV positive reporting unprotected intercourse. ${ }^{2}$ Between $30-46 \%$ of sexually transmitted HIV infections are transmitted by people who know they are infected with the virus. $^{3}$

A critical element of reducing HIV transmission risk is disclosure of HIV sero status by HIV positive individuals. Disclosure is recommended during post-test counseling since it supports risk reduction behaviours and facilitates access to prevention, care and treatment services for people living with HIV/AIDS (PLWHA), their partner(s) or infant(s). ${ }^{6}$

Disclosure may lead to safer sexual practices and, may also reduce the risk of re-infection with a resistant strain of HIV if both partners are HIVpositive. It can also decrease the risk of acquiring another STI if the discussion facilitates safer sex practices. In addition, disclosure may have greater public health benefit because it allows partners of HIV-positive individuals to make informed choices before initiating, or in some cases reinitiating sexual contact. It also provides information to individuals that may motivate them to practice safer sex. Furthermore, disclosure creates an opportunity for both parties to negotiate and discuss options and preferences for safer sex. When HIV-positive individuals do not disclose to their sexual partners, the partners may underestimate their own risk and may subsequently engage in less self-protective behaviours. ${ }^{7-9}$
Disclosure of HIV status is a planned and selective behaviour which responds to the person's balance of potential risks and benefits of secrecy and disclosure ${ }^{1}$. It might also be considered to be an expression of responsibility towards a spouse or sex partners. Disclosure to others, lovers, family or friends, has been shown to be a potent stressor, as individuals living with HIV/AIDS might fear negative reactions such as blame, rejection or violence. ${ }^{10-12}$ However, researchers have documented that HIV positive individuals experiencing stress who also disclose their positive status tend to feel better emotionally than those who do not disclose. ${ }^{13}$

Some people living with HIV/AIDS (PLWHA) tend to disclose their status to people to whom they are closely related, and who they truly trust, mostly family members such as spouses, parents, siblings, children, aunts and uncles. However, some others disclose their status to friends, neighbours, and even members of the public. PLWHA tend to share their status with family members due to the social ties they have and the psychosocial support they expect from them. ${ }^{24}$ However, this might not always be the case, as some people do not trust their family members as they do trust their friends.

In a cross-sectional study on rate, pattern and barriers to HIV sero status disclosure among 187 HIV positive individuals in Rivers State, Nigeria, it was found that the patients had disclosed their HIV sero-status to: parents (22.3\%), siblings $(9.7 \%)$, pastors $(27.8 \%)$, friends $(6.3 \%)$, family members $(10.4 \%)$ and sexual partners (23.6\%). Females were more likely to disclose their HIV sero status compared with males. Mothers were twice more likely to be confided in compared with fathers. ${ }^{36}$

In another review carried out in California, United States of America, five relational contexts were adopted to review disclosure of HIV positive sero status: with partners, family members, friends, healthcare professionals and in work settings. It was found that most people living with HIV disclosed to their sexual partners and family 
members, yet there was a significant minority who did not disclose. Rates of disclosure to employers ranged from $27 \%$ to $68 \%$, suggesting broad variability in perceived consequences of employment disclosures. Forty percent $(40 \%)$ of people living with HIV do not disclose to their healthcare professionals. ${ }^{37}$ In a comparative study in Brazil on patterns of self-disclosure across social support networks taking into consideration elderly, middle-aged and young adults in the United States who were HIV positive, it was found that elderly adults self-disclose more often to family than friends, while young adults selfdisclose to friends more often than to family. ${ }^{38}$

Another study carried out in Ilorin, Nigeria, used semi-structured interviewer-administered questionnaire to collect information on HIV status disclosure among 253 people aged between 26 and 58 years living with HIV/AIDS and accessing treatment at the University of Ilorin Teaching Hospital, Kwara State, Nigeria. Out of a total of $39.3 \%$ individuals that disclosed their HIV positive status to different audiences, $18.7 \%$ of them disclosed to their spouses while $20.6 \%$ disclosed to relatives, friends or co-workers. ${ }^{33}$

In a descriptive cross-sectional survey on HIV status disclosure among 270 randomly selected people living with HIV/AIDS at Family AIDS Support Organization (FASO) in Zimbabwe, it was found that $79 \%$ disclosed to the family, $72 \%$ disclosed to health workers and $70 \%$ disclosed to sexual partners.

\section{Reasons for disclosure}

The main reason for disclosure to family members were to obtain psychosocial and material support while the main reason for disclosure to the public was to give HIV/AIDS a face; and to the sexual partners it was to have safer sex. Knowing one's HIV status for a year or longer was significantly associated with disclosure to family, sexual partner and to the public. ${ }^{39}$

\section{Problem statement}

Regardless of massive efforts made by various stakeholders to reduce the prevalence of
HIV/AIDS in Nigeria, the country still carries the second heaviest burden of HIV in Africa and has an expanding population of people living with HIV. ${ }^{27}$ People diagnosed with HIV infection often face difficulties in disclosing to others their infection status. This factor affects efforts of reducing HIV prevalence. HIV status disclosure by some PLWHA brings about negative consequences including stigma, discrimination, abandonment, rejection, divorce, physical violence, denied socio-economic support and fear of being accused of infidelity. ${ }^{19,20,23}$ These outcome makes some HIV-infected individuals not to disclose their status. Non-disclosure of HIV status adversely affects efforts at reducing HIV prevalence and prevention of mother to child transmission of HIV/AIDS. ${ }^{28}$ With the realization of the central role played by disclosure in the prevention of HIV transmission, previous studies on HIV status disclosure have provided evidence on low rates of disclosure with a big variance of disclosure rates across countries. Disclosure rates in developing countries after diagnosis ranged from $16.7 \%$ to $86 \% \cdot{ }^{17,18}$ There is a paucity of information on HIV status disclosure and associated factors in urban and rural areas of Nigeria and none in Cross River State where the prevalence of HIV/AIDS is $7.1 \%$, a value higher than the national HIV prevalence of $3.4 \% .^{27}$ The few studies done in Nigeria on disclosure of HIV positive status were urban-based. This undermines the views of WHO and the Centre for Disease Control and Prevention (CDC) who emphasized disclosure. ${ }^{17,18}$ A study carried out in Zimbabwe found that HIV positive individuals who live in rural area were two times less likely to disclose their HIV status compared to those who live in urban area. ${ }^{28}$ The preferred audience of HIV status disclosure is not known in Cross River State because no study have been carried out on preferred audience of HIV status disclosure, let alone comparing it in urban and rural areas. 


\section{Justification of the study}

The prevention and control of HIV infection depend on the success of strategies to prevent new infections and treat currently infected individuals. HIV testing and counseling serves as a critical prevention and treatment tool in the control of the HIV epidemic. Within HIV testing and counseling programmes, emphasis is placed on the importance of HIV status disclosure among HIVinfected individuals, particularly to their sexual partners.

The rates of disclosure among the studies from the developing world are notably lower, yet, this is the area where HIV/AIDS is said to be ravaging. Although HIV status disclosure is emphasized by WHO and disclosure is part of the post-test counseling, there is a dearth of information on the preferred audience of HIV status disclosure since the prevalence of disclosure to different audience varies. The few studies done in Nigeria on disclosure of HIV positive status were urbanbased and yet did not consider the audience to whom the disclosure was made..

In view of the crucial roles that HIV disclosure plays on HIV prevention in general, it is instructive to carry out this study and document the magnitude of HIV status disclosure to different audience. This study will contribute to filling the existing knowledge gap and indicate proper intervention measures for promoting disclosure in urban and rural areas. This will in turn, hopefully reduce the spread and transmission of HIV in Cross River State.

\section{Objectives}

General Objective: To assess and compare preferred audience of disclosure of HIV sero status and its associated reasons among HIV positive individuals in urban and rural areas of Cross River State.

\section{Specific Objectives}

- To determine preferred audience of HIV status disclosure among HIV positive individuals in urban and rural areas of Cross River State.
- To compare preferred audience of HIV status disclosure among HIV positive individuals in urban and rural areas of Cross River State.

- To assess and compare reasons for HIV status disclosure to preferred audience among HIV positive individuals in urban and rural areas of Cross River State.

\section{Materials and Methods Study Area}

Cross River State (CRS) is located within the tropical rain forest belt of Nigeria. It is one of the six states in the South-South geopolitical zone of Nigeria. There are 18 Local Government Areas (LGAs) in the State out of which, according to Cross River State Planning Commission, five are urban (Calabar Municipality, Calabar South, Ikom, Obudu and Ogoja); two are semi-urban (Akamkpa and Yakurr) while eleven are rural (Abi, Akpabuyo, Bakassi, Bekwara, Biase, Boki, Etung, Obanliku, Obubra, Odukpani and Yala).The study was carried out in two HIV treatment health facilities, one located in Calabar Municipality and another located in Akpabuyo Local Government Area.

Calabar Municipality lies between latitude $04^{0} 15^{1}$ and $5^{0}$ North and longitude $08^{0} 25^{1}$ East. In the North, the Municipality is bounded by Odukpani Local Government Area, in the North-east by the Quo River. Its Southern shores are bounded by the Calabar River and Calabar South Local Government Area. It has an area of 331.551 square kilometres and a population of 183,681 people. ${ }^{57}$ Calabar Municipality is both the capital city of Cross River State and the headquarters of the southern senatorial district. There are ten wards in the LGA. Two ethnic groups form the indigenous population, namely the Quos and the Efiks. However, because of its cosmopolitan status, there abound people from all parts of the State and Nigeria in the city. The main occupational groups are civil servants, business men, farmers, traders and fishermen. 
Akpabuyo Local Government Area became autonomous on Tuesday $27^{\text {th }}$ August, 1991 following its creation from the former Odukpani Local Government Area. It has a population of 272,262 people and is located in the southern senatorial district with headquarters at Ikot Nakanda. ${ }^{57}$ It consist of 10 (ten) council wards, namely Idundu/Anyananse, Atimbo East, Atimbo West, IkotEdemOdo, Eneyo, IkotNakanda, IkotEyo, Ikang North, Ikang South and Ikang Central. The major ethnic groups are the Quos and the Efuts. The major languages spoken are Efik and English, while all the major ethnic groups share a common cultural and ancestral heritage. The people of Akpabuyo are predominantly farmers and fishermen. Akpabuyo Local Government Area lies between latitude $04^{0} 5^{1}$ and $05^{0} 40^{1}$ and longitude $08^{0} 25^{1}$ and $08^{0} 32$ East. It lies within the vegetation belt of Southern Nigeria and shares the Atlantic Coastline with Bakassi in the East and the Republic of Cameroon in the West. St Joseph Hospital in Akpabuyo is the comprehensive treatment site to provide HAART services to the rural areas which include all the ten wards that make up Akpabuyo Local Government Area. The study was carried out at the Special Treatment Clinic, formerly called the President's Emergency Plan for AIDS Relief (PEPFAR) clinic of the University of Calabar Teaching Hospital, Calabar Municipality (urban) and St Joseph Hospital, Akpabuyo Local Government Area (rural). These are the facilities that give out HAART and other HIV-related services to HIV positive individuals in the areas. The Special Treatment Clinic is the centre for the implementation of the President's Emergency plan for Aids Relief (PEPFAR) by the United States Agency for International Development (USAID) since June 2005. It has since been responsible for the provision of care and support services for People living with HIV/AIDS (PLWHA) as well as one of the major centres where PLWHA both in Cross River State and other neighbouring States receive anti retroviral therapy. The patient population is about 4,500 , of which about 2,000 are on treatment and this treatment list keeps increasing by the day. The clinic is run under three units namely the paediatric, adult and the Prevention of Mother to Child transmission (PMTCT) clinics. Services are provided by three doctors and four nurses trained in delivering health care to PLWHA. The Services are also provided by doctors from Family Medicine, Paediatrics, Obstetrics and Gynaecology, Psychiatry and Community Medicine Departments all drawn from the University of Calabar Teaching Hospital, Calabar. St Joseph Hospital, Akpabuyo is the only General Hospital in Akpabuyo Local Government Area. The HIV/AIDS services here started in October, 2008 as a comprehensive Health Clinic to provide care and support services for People living with HIV/AIDS. The Comprehensive Health Clinic is funded principally by SIDHAS (Strengthening Integrated Delivery of HIV/AIDS Services) which is being implemented by FHI 360. Presently, the patient load is about 1600 with over 400 on treatment. The main clinic day is Wednesday but patients that have need of being seen are attended to any day of the week. It is run under the Adult, Paediatric and PMTCT clinics by doctors, nurses, laboratory scientists, pharmacists and other support staff. The health facility serves the people fromthe different rural Communities in Akpabuyo Local Government Area.

\section{Study design}

The study design was cross-sectional comparative study on disclosure of sero status among HIV positive individuals in urban and rural areas of Cross River State, using mixed methods that comprised of interview-administered semistructured questionnaire (for quantitative data) and Focus Group Discussion (for qualitative) for data collection from respondents.

\section{Study population}

The study population was HIV positive individuals aged 18 years and above obtaining HAART from the selected health facilities in 
urban and rural areas of Cross River State. The age limit for the study was 18 years and above because the study intended to include only the adult population of HIV positive individuals in the two selected areas who met the inclusion criteria.

\section{Duration of study}

The study lasted for a period of sixteen (16) weeks (from $10^{\text {th }}$ June, 2014 to $30^{\text {th }}$ September, 2014).

\section{Inclusion Criteria}

HIV positive individuals aged 18 years and above receiving HAART in the health facilities in the selected urban and rural areas of Cross River State who gave informed consent were included.

\section{Exclusion Criteria}

Individuals who were not HIV positive or those who were HIV positive but were aged less than 18 years, refused to give informed consent or who were not obtaining HAART in the selected health facilities in the selected urban and rural areas of Cross River State were excluded.

\section{Sample Size Determination}

The sample size was determined using the formula for comparing two independent groups ${ }^{58}$

$$
\begin{gathered}
\mathbf{n}=\left\{\mathbf{Z}_{\beta} \sqrt{ }\left[\mathbf{P}_{1}\left(1-\mathbf{P}_{1}\right)+\mathbf{P}_{2}\left(\mathbf{1}-\mathbf{P}_{2}\right)\right]+\mathbf{Z}_{\alpha} \sqrt{ }[\mathbf{2 P}(1-\mathbf{P})]\right\}^{2} \\
\left(\mathbf{P}_{2}-\mathbf{P}_{1}\right)^{\mathbf{2}}
\end{gathered}
$$

Where $\mathrm{n}=$ sample size of each comparative arm.

$\mathrm{Z} \alpha=$ Percentage point of the normal distribution corresponding to the (two sided) significance level of $5 \%=1.96$

$\mathrm{Z}_{\beta}=$ One sided percentage point of the normal distribution corresponding to $\beta$ (100\% -Power): at Power $80 \%(\beta=20 \%), Z_{\beta}=0.84$

$\mathrm{P}_{1}=$ prevalence of HIV positive status disclosure in urban areas $=40 \%(0.4)$ from a previous study in Ilorin among people living with HIV accessing treatment at the University of Ilorin Teaching Hospital, Ilorin, Nigeria. ${ }^{29}$

$\mathrm{P}_{2}=$ prevalence of HIV positive status disclosure in rural areas $=30 \%(0.3)$ from a previous study done in a rural Community in South Africa. ${ }^{59}$

$\mathrm{P}=[\mathrm{P} 1+\mathrm{P} 2] / 2$.

$$
=[0.4+0.3] / 2=0.35
$$

Assuming a power of $80 \%$ and an alpha level of $5 \%$,

$$
\begin{aligned}
& \mathrm{n}=\{0.84 \sqrt{[0.4(1-0.4)}+0.3(1-0.3)]+ \\
& 1.96 \sqrt{ }[2 \mathrm{x} 0.35(1-0.35)]\}^{2} \\
& \quad=145.5
\end{aligned}
$$

To take care of non-response, $10 \%$ of the calculated minimum sample size was added.

$10 \%$ of $145.5=14.55$

Hence, $145.5+14.55=159.55$, approximately $=$ 160.

Thus final calculated required sample size, $\mathrm{n}=$ 160 for each comparative arm

The total required sample size, $\mathrm{N}=320$ for the study.

\section{Sampling Technique}

A multistage sampling technique was used to select the study participants.

Stage one: Simple random sampling technique was used in the first stage to select the Local Government Areas where the study was carried out. All the LGAs with HIV diagnosis and treatment centre obtained from the Cross River State agency for the control of AIDS were stratified into rural and urban LGAs based on CRS Public health classification. According to the Cross River State Planning Commission, Out of the 18 Local Government Areas (LGAs) in Cross River State, five are urban (Calabar Municipality, Calabar South, Ikom, Obudu and Ogoja), two are semi-urban (Akamkpa and Yakurr) and eleven are rural (Abi, Akpabuyo, Bakassi, Bekwara, Biase, Boki,

Etung, Obanliku, Obubra, Odukpani and Yala). One LGA was selected from each stratum using simple random sampling technique (balloting): All the five urban Local Government Areas were numbered serially from 1 to 5 on 5 pieces of papers of equal size which were folded and shuffled. One was drawn out and noted to be Calabar Municipality. For the rural site, all the eleven rural Local Government Areas were numbered serially from 1 to 11 on 11 pieces of 
papers of equal size which were folded and shuffled. One was drawn out and noted to be Akpabuyo Local Government Area.

Stage two: Purposive sampling technique was used to select the health facilities (one in Calabar Municipality and one in Akpabuyo Local Government Area). The Special Treatment Clinic at the University of Calabar Teaching Hospital (formerly called PEPFAR clinic) was purposively chosen as the urban study site because it is the only comprehensive site for HIV treatment services in Calabar Municipality while St. Joseph Hospital, Akpabuyo was selected purposively as the study site for rural because it is the only comprehensive centre for HIV/AIDS services in Akpabuyo Local Government Area. Other health facilities only carry out screening test for HIV. Those found to be positive are referred to this comprehensive centre for HIV confirmation and treatment services.

Stage three: Total sampling of HIV positive individuals that attended the clinics at the study facilities was done on every clinic day (Tuesdays and Thursdays for the urban site and Wednesdays for the rural site).All those who met the inclusion criteria were identified and those that gave informed consent were recruited into the study until a total of 160 respondents were enrolled from the urban site and another 160 enrolled from the rural site, giving a total of 320 respondents that participated in the study from both study areas.

\section{Study Instruments}

The study instruments were semi structured interviewer-administered pre-tested questionnaire and a semi-structured interview guide for focus group discussion.

The semi-structured interviewer-administered questionnaire consisted of three sections:

Section A: Information on respondent's sociodemographic characteristics

Section B: Disclosure of sero status by HIV positive individuals/preferred audience of disclosure of sero status by HIV positive individuals
Section C: Determinants of disclosure of sero status by HIV positive individuals

\section{Pretesting of questionnaire}

The questionnaire was pretested in General Hospital, Calabar among 20 HIV positive individuals whose selection was done by convenience sampling. Appropriate amendments were made to the questionnaire from the responses obtained. The final questionnaire was adapted based on findings from pretesting as well as the Focus Group Discussions (FGD).

\section{Training of Research assistants}

Two research assistants were trained to assist in administering the questionnaire. Training of research assistants was conducted twice in the seminar room of the Department of Community Medicine, University of Calabar Teaching Hospital, Calabar. Both research assistants were University graduates. The training included a basic introduction of HIV/ AIDS, meaning of disclosure of HIV positive status, importance of disclosure of HIV positive status, consequences of non disclosure, confidentiality and respecting respondents' decisions. The research assistants were supervised by the principal investigator after the training to ensure that the questionnaires were properly administered.

\section{Data collection methods}

Data collection was in two parts

Quantitative data collection: Intervieweradministered semi-structured questionnaire for the study were administered in English language by two trained research assistants. The participants in the selected health care facilities were interviewed in a quiet place devoid of inputs from any other person. This was to eliminate influence from other persons around, and to get the participant's candid response to the questions. The research assistants wrote down the answers or tick the chosen option where appropriate on the questionnaire. 


\section{Data Management and Analysis Quantitative data}

Completed and returned questionnaires were inspected daily by the principal investigator to detect errors, and omissions to ensure completeness of entry. Questionnaire were manually sorted out, serially numbered and coded before entry and cleaned following entry into the computer for statistical analysis using SPSS version 20.0. Data analysis was done using descriptive statistics (Frequency, proportions, means and standard deviation) to summarize variables. Inferential statistics (chi square, to test the significance of association between two categorical variables) was used to test for significance at 5\%level of significance. Variables were subjected to multiple logistic regression analysis to identify the true determinants of disclosure of HIV sero status. Determinants were also at $5 \%$ level of significance.

\section{Ethical Consideration}

Ethical clearance was obtained from the research ethics committee of the University of Calabar Teaching Hospital, Calabar and, Cross River State Ministry of Health Ethics Committees.

Informed consent was also sought for and obtained from the participants before inclusion in this study. The participants were informed of the purpose of the research and their right to participate or refuse to participate in the study without any punishment or denial of benefits due them. They were also informed of the time they might have to sacrifice in responding to the questionnaire if eventually they decide to participate in the study. Participants were assured of confidentiality of all information given since names and other information that could be traced back to them will not be collected.

Socio-demographic characteristics of respondents

4.6.1 Socio-demographic characteristics of respondents by study area

Table 5 shows the socio-demographic characteristics of respondents by study area. A total of 320 respondents participated in the study out of which 160 (50.0\%) were PLWHA assessing treatment in the urban area while the remaining $160(50.0 \%)$ were PLWHA assessing treatment in the rural area. The mean age of urban respondents was $38.1 \pm 10.4$ years while that of the rural respondents was $35.4 \pm 11.0$ years. There was a statistically significant difference between the mean ages of urban and rural respondents $(t=2.330, p=0.020)$. Majority of respondents in both urban and rural areas belong to the age group 25-34 and 35-44. However, the rural respondents population was significantly younger $(\mathrm{p}=0.010)$. A higher proportion $228(71.2 \%)$ of respondents in both areas were female and almost all were Christians, 158 (98.8\%) and 159 (99.4\%) in urban and rural respectively. No significant difference was observed in terms of religious affiliations in both locations $(\mathrm{p}=0.223)$. Majority of respondents in both groups were Efik and Ibibio/Anang but a significantly higher proportion of the rural respondent population were Efik $(\mathrm{p}<0.001)$. Majority of the respondents $154(96.3 \%)$ in rural compared with $142(88.8 \%)$ in urban were residing within Cross River State. This was statistically significant $(\mathrm{p}=0.011)$.

Table 5: Socio-demographic characteristics of respondents by study area

\begin{tabular}{|c|c|c|c|c|c|}
\hline Variable & $\begin{array}{c}\text { Urban } \\
(n=160) \\
\text { Freq. }(\%)\end{array}$ & 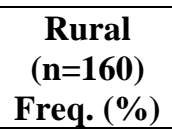 & $\begin{array}{c}\text { Total } \\
(\mathrm{N}=320) \\
\text { Freq. }(\%)\end{array}$ & $\chi^{2}$ & p- value \\
\hline \multicolumn{6}{|l|}{ Age (years) } \\
\hline$<25$ & $9(5.6)$ & $29(18.1)$ & $38(11.9)$ & & \\
\hline $25-34$ & $57(35.6)$ & $45(28.1)$ & 102(31.9) & & \\
\hline $35-44$ & $53(33.2)$ & $50(31.3)$ & $103(32.2)$ & 13.216 & $0.010 *$ \\
\hline $45-54$ & $28(17.5)$ & $28(17.5)$ & $54(17.5)$ & & \\
\hline$>55$ & $13(8.1)$ & $8(5.0)$ & $21(6.5)$ & & \\
\hline Mean \pm SD & $38.1 \pm 10.4$ & $35.4 \pm 11.0$ & $36.7 \pm 10.8$ & $2.330(\mathrm{t}$-test $)$ & 0.020* \\
\hline
\end{tabular}




\begin{tabular}{|l|c|c|c|c|c|}
\hline Sex & & & & & \\
\hline Male & $47(29.4)$ & $45(28.1)$ & $92(28.8)$ & & \\
\hline Female & $113(70.6)$ & $115(71.9)$ & $228(71.2)$ & 0.061 & 0.805 \\
\hline Religion & & & & & \\
\hline Christianity & $158(98.8)$ & $159(99.4)$ & $317(99.1)$ & & \\
\hline Islam & $2(1.2)$ & $1(0.6)$ & $3(0.9)$ & 3.003 & 0.223 \\
\hline Tribe & & & & & \\
\hline Ekoi & $6(3.8)$ & $3(1.9)$ & $9(2.8)$ & & \\
\hline Efik & $41(25.6)$ & $75(46.9)$ & $116(36.3)$ & 36.936 & $<\mathbf{0 . 0 0 1 *}$ \\
\hline Ibibio/Anang & $60(37.5)$ & $69(43.1)$ & $129(40.3)$ & & \\
\hline$* *$ Others & $53(33.1)$ & $13(8.1)$ & $66(20.6)$ & & \\
\hline $\begin{array}{l}\text { Normal place of } \\
\text { residence }\end{array}$ & & & & & \\
\hline & & & & & \\
\hline Within Cross River & $142(88.8)$ & $154(96.3)$ & $296(92.5)$ & 6.486 & $\mathbf{0 . 0 1 1 *}$ \\
\hline Outside Cross River & $18(11.2)$ & $6(3.7)$ & $24(7.5)$ & & \\
\hline
\end{tabular}

*Statistically significant

**others include Ijaw, Ibo, Ejagham, Yoruba and Hausa

\section{Persons to whom respondents disclosed their} HIV status by study area

Figure 2 shows all the audience to whom respondents disclosed their HIV status. The highest number of married/cohabiting respondents reported they disclosed to their spouse $141(31.1 \%)$. This was higher in the urban $89(36.2 \%)$ than in the rural area $52(25.0 \%)$. This was followed by disclosure to biological relative
$77(31.3 \%)$ in the urban compared with $49(23.6 \%)$ in the rural area. More respondents reported disclosure to their mother $26(12.5 \%)$ in the rural compared with $19(7.7 \%)$ in the urban area. Audience of disclosure to whom the least number of respondents disclosed their HIV status to in both study area was work colleague $4(2.0 \%)$ by urban and $1(0.5 \%)$ by rural respondents

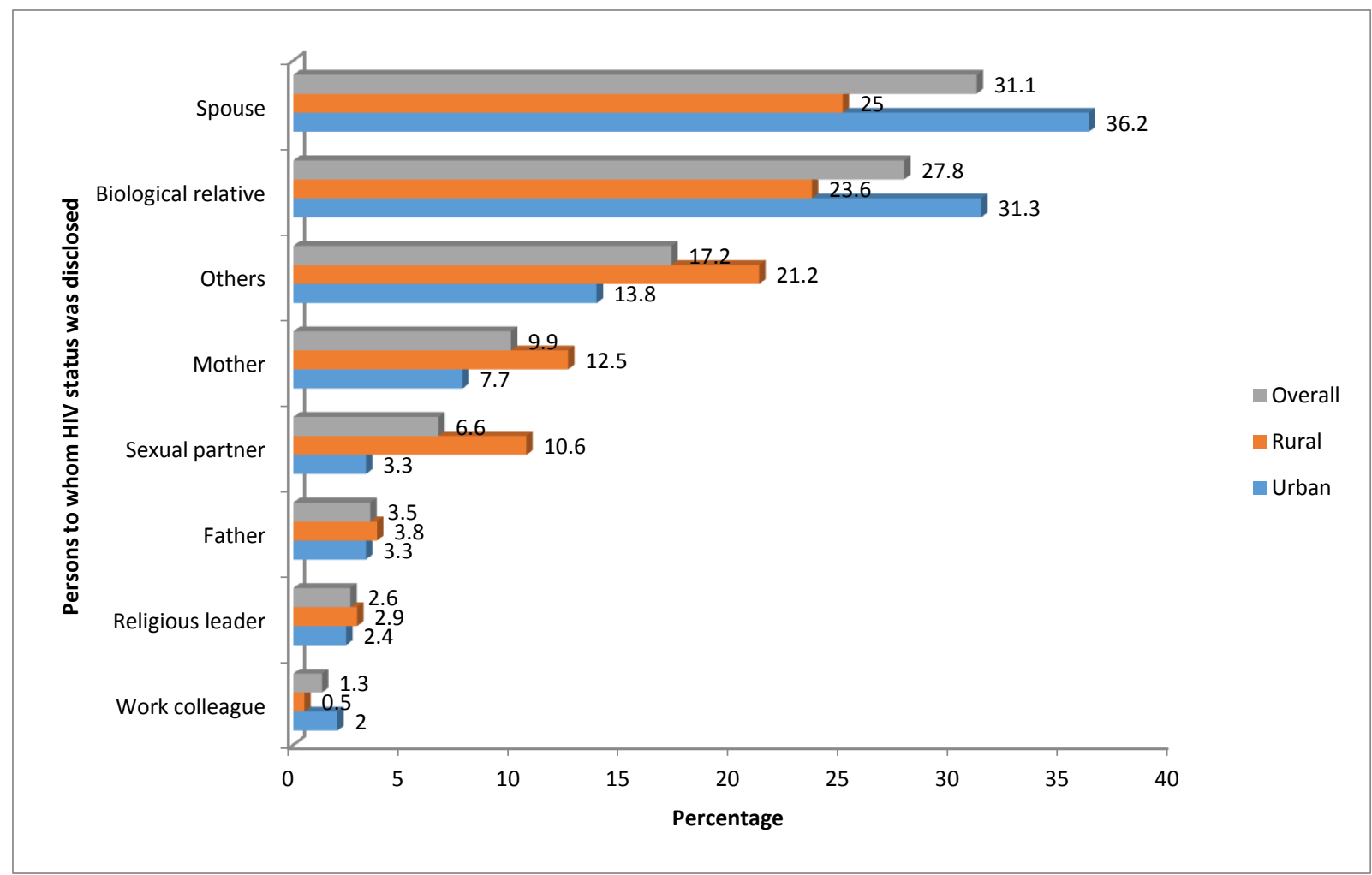

Figure 2: Persons to whom respondents disclosed their HIV status *Others include friends and $17.2 \%$ church member 


\section{Persons to whom respondents first disclosed HIV status by study area}

Persons to whom respondents first disclosed their HIV status is shown in figure 3 . Highest number of married respondents reported they first disclosed their status to their spouse; higher in urban $68(45.3 \%)$ than rural $42(33.1 \%)$. This was followed by disclosure to biological relative; $43(28.7 \%)$ in urban compared with $28(22.0 \%)$ in rural. Respondents that disclosed first to others (friends, church member and children) were $22(17.3 \%)$ in rural compared with $15(10.7 \%)$ in urban. Other audiences of first disclosure as reported by respondents are illustrated in figure 3 .

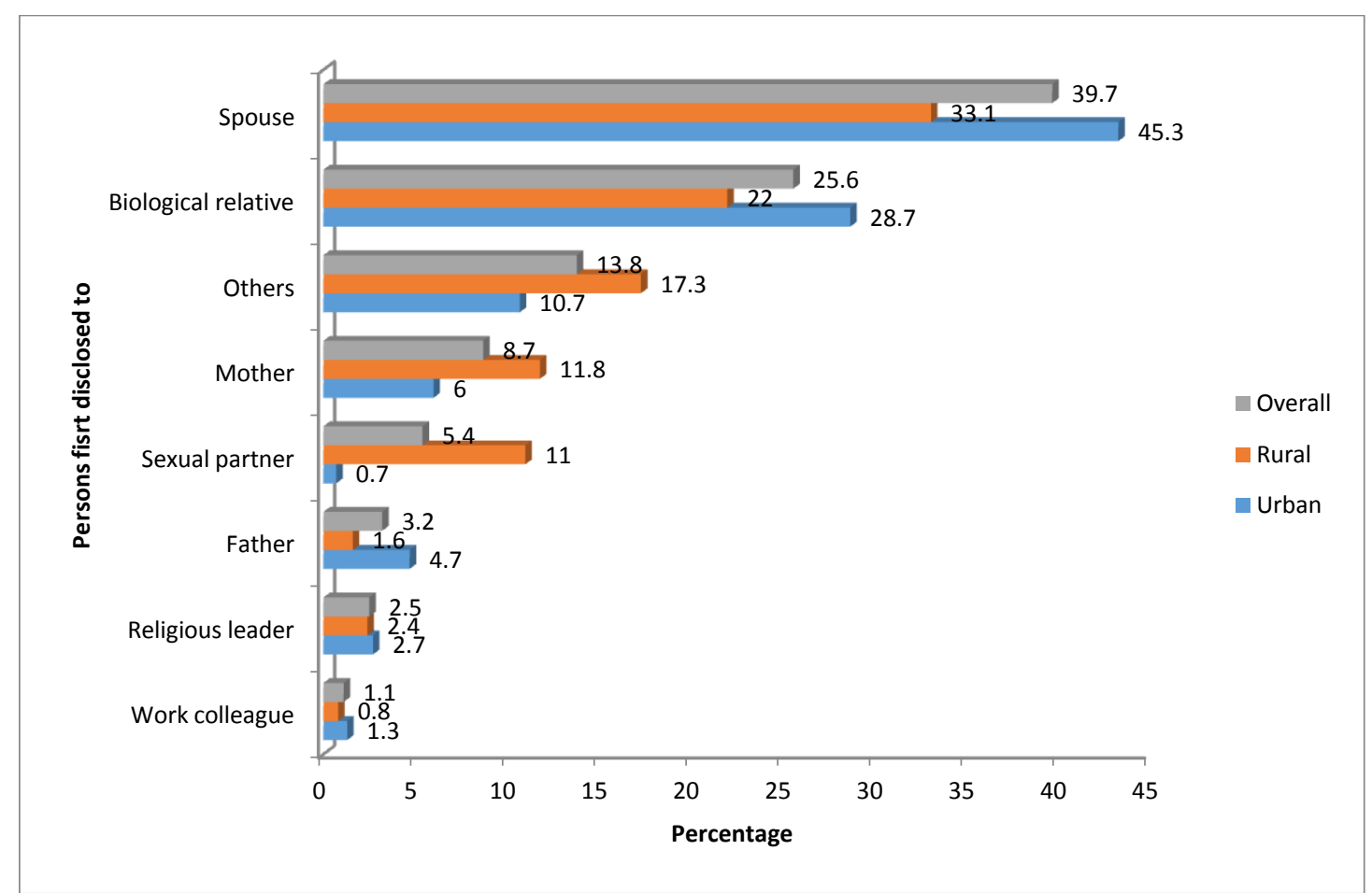

Figure 3: Persons to whom respondents first disclosed their HIV status by study area *Others include friends, church member and children

\section{Respondents' perception regarding HIV status disclosure, and awareness of partner's/spouse's HIV status by study area}

Table 11shows whether respondents thinks it's important to disclose, had disclosed to sexual partner/spouse, aware of partner's/spouse's status and whether worried about others knowing status by study area.

A higher proportion of respondents 233(72.8\%) said it was not important to disclose HIV status, $122(76.3 \%)$ in rural compared with 111(69.4\%) in urban. This difference was not statistically significant $(p=0.167)$.Overall, a little above half respondents $168(52.5 \%)$ had disclosed status to spouse or sexual partner. This was significantly higher in urban $97(60.6 \%)$ compared with rural $71(44.4 \%)$ respondents $(\mathrm{p}=0.004)$. In both urban and rural areas, a higher proportion of respondents $173(54.1 \%)$ were aware of the HIV status of their sexual partner/spouse, this was higher $97(60.6 \%)$ in the urban compared with $76(47.5 \%)$ in the rural. It was statistically significant $(p=0.018)$. There was also a statistically significant difference between the proportion of rural 144(90.0\%) and urban $115(71.9 \%)$ who were worried about others knowing their HIV status $(\mathrm{p}<0.001)$. 
Table 11: Respondents' perception regarding HIV status disclosure, and awareness of partner's/spouse's HIV status by study area

\begin{tabular}{|l|c|c|c|c|c|}
\hline 3Variable & $\begin{array}{c}\text { Urban } \\
(\mathbf{n = 1 6 0} \\
\text { Freq.(\%) }\end{array}$ & $\begin{array}{c}\text { Rural } \\
(\mathbf{n = 1 6 0 )} \\
\text { Freq.(\%) }\end{array}$ & $\begin{array}{c}\text { Total } \\
(\mathbf{N = 3 2 0}) \\
\text { Freq.(\%) }\end{array}$ & $\chi^{\mathbf{2}}$ & p- value \\
\hline Important to disclose HIV status? & & & & & \\
\hline Yes & $49(30.6)$ & $38(23.7)$ & $87(27.2)$ & 1.910 & 0.167 \\
\hline No & $111(69.4)$ & $122(76.3)$ & $233(72.8)$ & & \\
\hline Disclosed to sexual partner/spouse? & & & & & \\
\hline Yes & $97(60.6)$ & $71(44.4)$ & $168(52.5)$ & 8.471 & $\mathbf{0 . 0 0 4}$ \\
\hline No & $63(39.4)$ & $89(55.6)$ & $152(47.5)$ & & \\
\hline Aware of partner's/spouse's status? & & & & & \\
\hline Yes & $97(60.6)$ & $76(47.5)$ & $173(54.1)$ & 5.549 & $\mathbf{0 . 0 1 8 ^ { * }}$ \\
\hline No & $63(39.4)$ & $84(52.5)$ & $147(45.9)$ & & \\
\hline $\begin{array}{l}\text { Worried about others knowing your } \\
\text { status? }\end{array}$ & & & & & \\
\hline Yes & $115(71.9)$ & $144(90.0)$ & $259(80.9)$ & 17.034 & $<\mathbf{0 . 0 0 1 *}$ \\
\hline No & $45(28.1)$ & $16(10.0)$ & $61(19.1)$ & & \\
\hline
\end{tabular}

\section{Respondents' reasons for disclosing their HIV} status

Figure 4 shows respondents' reasons for disclosing their HIV status to preferred audience. A greater proportion of respondents in urban reported that they disclosed in order to get encouragement, advice or to encourage others
16(50.0\%). The second highest reason reported was to help their spouse/sex partner go for test $7(21.9 \%)$. Among the rural respondents, the highest reason reported was to enable them take their HAART freely $16(44.4 \%)$. Other reasons reported are illustrated in figure 4.

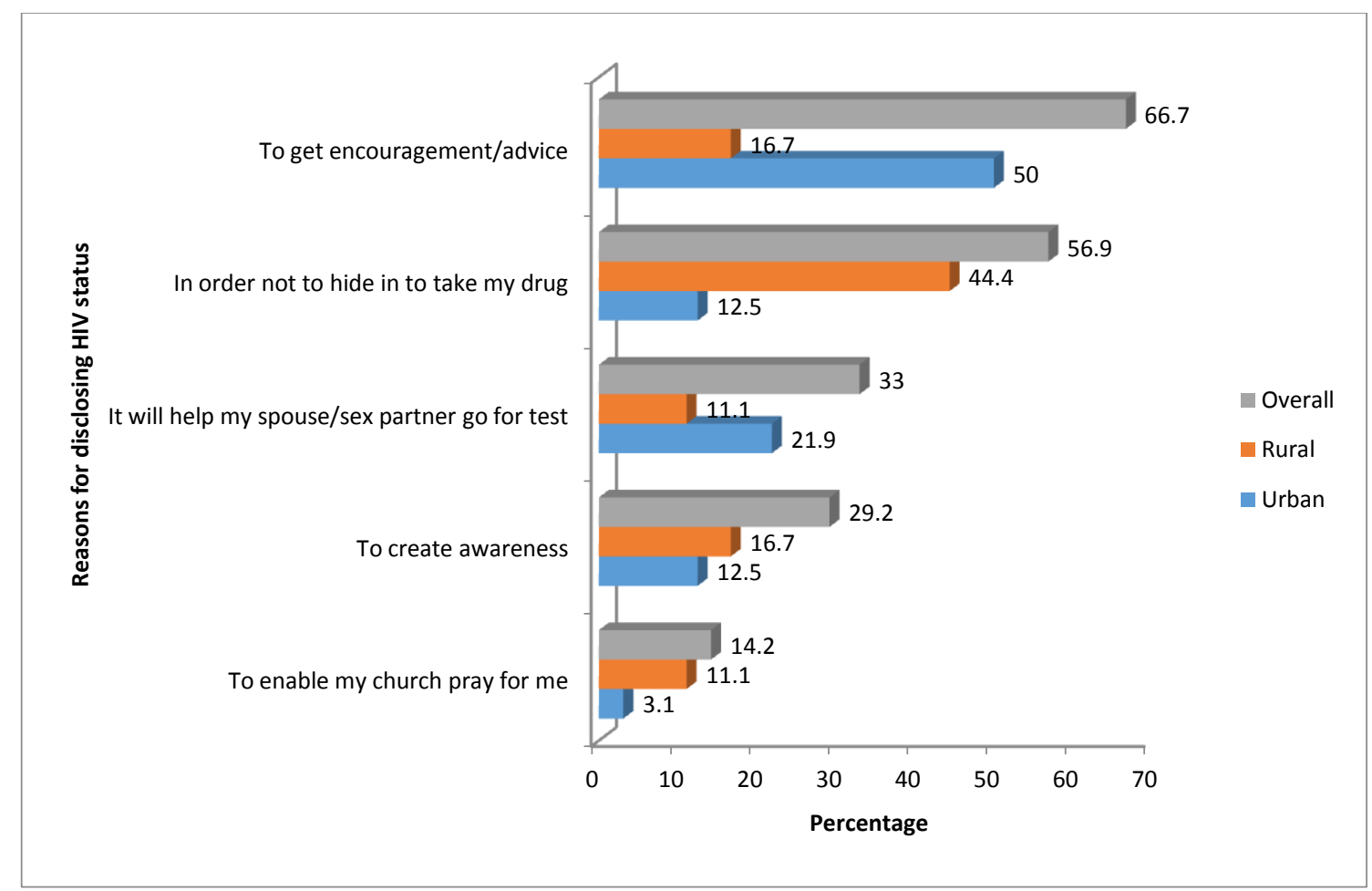

Figure 4: Respondents' reasons for disclosing their HIV status by study area 


\section{Discussion}

The study found that the highest number of married/cohabiting respondents reported they disclosed to their spouse (31.1\%). This was higher in the urban (36.2\%) than in the rural area (25.0\%). This was followed by disclosure to biological relative $(31.3 \%)$ in the urban compared with $23.6 \%$ in the rural area. This was congruent to the finding of a cross-sectional study on rate, pattern and barriers to HIV sero status disclosure among HIV positive individuals in Rivers State, Nigeria, where the individuals had disclosed to parents $(22.3 \%)$, siblings $(9.7 \%)$, pastors $(27.8 \%)$, friends $(6.3 \%)$, family members $(10.4 \%)$ and sexual partners (23.6\%).Mayfield et al in their study also found that most people living with HIV disclosed to their sexual partners and family members ${ }^{37}$. Disclosure to spouses and siblings may be no enable the HIV positive individual take their drugs without hiding while disclosure to sex partner/spouse was to enable such go for test to know their status. In the present study, overall, $17.2 \%(21.2 \%$ in rural and $13.8 \%$ in urban) of respondents had disclosed to friends and church members. Parker and Parrott in their study in Brazil also had a similar finding in addition to the fact that elderly adults self-disclose more often to family than friends, while young adults selfdisclose to friends more often than to family. ${ }^{38}$

The present study found that more respondents reported disclosure to their mother $(12.5 \%)$ in the rural compared with $(7.7 \%)$ in the urban area. This is also comparable to the findings of Akani and Erhabor in Rivers State mothers were twice more likely to be confided in compared with fathers. ${ }^{36}$

Audience of disclosure to whom the least proportion of respondents disclosed their HIV status to in both study area was work colleague $(2.0 \%)$ by urban and $(0.5 \%)$ by rural respondents first disclosed HIV status

Highest number of married respondents reported they first disclosure of their HIV status to their spouse; higher in urban $(45.3 \%)$ than rural (33.1\%). This was followed by disclosure to biological relative; $(28.7 \%)$ in urban compared with $(22.0 \%)$ in rural. The proportion of respondents that disclosed first to others (friends, church member and children) was $17.3 \%$ in rural compared with $10.7 \%$ in urban. This choice, according to respondents hinged on the need for prayers, encouragement and advice or counselling from the confidants.

\section{References}

1. Joint United Nations Programme on HIV/AIDS $\quad$ (UNAIDS). 2014 Epidemiological slides-GAP Report; 2014. Accessed December $24^{\text {th }} 2014$ from kff.org/global-health-policy/fact-sheet/theglobal-hivaids-epidemic.

2. Bunnell R, Ekwaru JP, Solberg P, Wamai $\mathrm{N}$, Bikaako-Kajura W. Changes in sexual behaviour and risk of HIV transmission after antiretroviral therapy and prevention intervention in rural Uganda. AIDS. 2006;20(1):85-92.

3. Marks G, Crepaz N, Janssen RS. Estimating sexual transmission of HIV from persons aware and unaware that they are infected with the virus in the USA. AIDS. 2006;20(10):1447-50.

4. Sullivan KM. Male self-disclosure of HIVpositive serostatus to sex partners: a review of the literature. $\mathbf{J}$ Assoc Nurses AIDS Care. 2005;16(6):33-47.

5. Simbayi LC, Kalichman SC, Strebel A, Cloete A, Henda N, Mqeketo A. Disclosure of HIV status to sex partners and sexual risk behaviours among HIVpositive men and women, Cape Town, South Africa. Sex Transm Infect. 2007;83(1):29-34.

6. Kalichman SC, Nachimson N. Selfefficacy and disclosure of HIV-positive serostatus to sex partners. Health Psycho. 1999;18:281-7.

7. Ciccarone DH, Kanouse DE, Collins RL, Miu A, Chen JL, Morton SC. Sex without disclosure of positive HIV serostatus in a US probability sample of persons 
receiving medical care for HIV infection. Am J Public Health. 93(6):949-54.

8. Derlega VJ, Winstead BA, Oldfield IE, Barbee AP. Close relationships and social support in coping with HIV: a test of sensitive interaction systems theory. AIDS Behav. 2003;7(2):119-29.

9. Zea MC, Reisen CA, Poppen PJ, Diaz RM. Asking and telling: communication about HIV status among Latino HIV-positive gay men. AIDS Behav. 2003;7(2):143-52.

10. Holt R, Court P, Vedhara K, Nott KH, Holmes J, Snow MH. The role of disclosure in coping with HIV infection. AIDS Care. 1998;10(1):49-60.

11. Kalichman SC, DiMarco M, Austin J, Luke W, Difonzo K. Stress, social support, and HIV-status disclosure to family and friends among HIV-positive men and women. J Behav Med. 2003;26(4):315-32.

12. Medley A, Garcia-Moreno C, McGill S, Maman S. Rates, barriers and outcomes of HIV serostatus disclosure among women in developing countries: implications for prevention of mother-to-child transmission programmes. Bull World Health Organ. 2004;82(4):299-307.

13. Serovich JM. A test of two HIV disclosure theories. AIDS Education and Prevention. 2001;13(4):355-64.

14. UNAIDS. Opening up the HIV/AIDS epidemic. Guidance on encouraging beneficial disclosure, ethical partner counselling and appropriate use of HIV case-reporting. Geneva Switzerland; 2000:8-10.

15. Almeida NA. Prevalence and factors affecting HIV status disclosure among pregnant women receiving PMTCT services in Dares Salaam. 2005:13-4.

16. Vyavaharkar M, Moneyham L, Corwin S, Tavakoli A, Saunders R, Annang L.. HIV disclosure, Social support and Depression among HIV infected African American Women Living in the Rural Southeastern
United States. AIDS Education and Prevention. 2011;23 (1):78-90.

17. UNAIDS. Counselling and HIV/AIDS. UNAIDS best practices collection. Geneva; 1997:3-4.

18. Centre for Diseases Control and Prevention. Revised guidelines for HIV counselling, testing and referral. Morbidity and Mortality weekly report. 2002;50:1-57.

19. Kadowa I, Nuwaha F. Factors influencing disclosure of HIV positive status in Mityana district of Uganda. African Health Sciences. 2009;9(1):9(1):26-33.

20. Mohammed H, Kissinger P. Disclosure of HIV serostatus to sex partners in rural Louisiana. AIDS Care. 2006;18 Suppl 1:62-9.

21. Ogundahunsi OA, Daniel OJ, Oladapo OT. Adherence to antiretroviral drugs among AIDS patients in Sagamu, Nigeria. International Journal of Biomedical and Health Sciences. 2008;(2):4-9.

22. Derlega VJ, Metts S, Petronio S, Margulis ST. Self-disclosure. Newbury Park. CA: Sage. 1993:152-8.

23. Makin JD, Forsyth BW, Visser MJ, Sikkema KJ, Neufeld S, Jeffery B. Factors Affecting Disclosure in South African HIV-Positive Pregnant Women. AIDS Patient Care and STDs. 2008;22(11):90716.

24. Lugalla J, Yoder S, Sigalla H, Madihi C. Social context of disclosing HIV test results in Tanzania. Culture, Health and Sexuality. 2011;19:32-9.

25. Deribe K, Woldemichael K, Njau BJ, Yakob B, Biadgilign S, Amberbir A. Gender differences regarding barriers and motivators of HIV status disclosure among HIV-positive service users. Journal of Social Aspects of HIV/AIDS. 2010;7(1):30-9.

26. Adejumo A. The influence of psychosocial factors and the effectiveness of 
behavioural techniques on HIV sexual risk behaviour among adolescents in Ibadan, Nigeria. IFE PsychologIA. 2004:211-31.

27. National Agency for the Control of AIDS (NACA), Federal Republic of Nigeria. GLOBAL AIDS RESPONSE. Country Progress Report Nigeria. 2014. Accessed $24^{\text {th }} \quad$ December 2014 from www.unaids.org/en/dataanalysis.

28. Mucheto P, Chadambuka A, Shambira G, Tshimanga M, Gombe N, Nyamayaro W. Determinants of nondisclosure of HIV status among women attending the prevention of mother to child transmission programme, Makonde district, Zimbabwe. Pan Afr Med J. 2011;8:51-59.

29. Suzanne M, Amy M. Gender Dimensions of HIV Status Disclosure to Sexual Partners: Rates, Barriers and Outcomes. WHO review paper, 2004: 5-8. Accessed August $\quad 2^{\text {nd }} \quad 2014$ from htt://www.who.int/gender/documents/en/

30. Grey RH, Kiwanuka N, Quinn TC, Sewankambo NK, Serwadda D, WabwireMangen F. Male circumcision and HIV acquisition and transmission: Cohort studies in Rakai, Uganda. AIDS. 2001; 14(15): 2371-81.

31. Wong LH, Rooyen HV, Modiba P, Richter L, Gray G, Paeds Fl. Test and Tell: Correlates and Consequences of Testing and Disclosure of HIV Status in South Africa (HPTN 043 Project Accept). Journal of Acquired Immune Deficiency Syndrome. 2009;50(2):215-22.

32. Patel R, Ratner J, Gore-Felton C, Kadzirange G, Woelk G, Katzenstein D. HIV disclosure patterns, predictors, and psychosocial correlates among HIV positive women in Zimbabwe. AIDS Care: Psychological and Socio-medical Aspects of AIDS/HIV. 2012;24 (3):358-68.

33. Salami AK, Fadeyi A, Ogunmodede JA, Desalu OO. Status disclosure among people living with HIV/AIDS in Ilorin,
Nigeria. West Afr J Med. 2011; 30(5):35963.

34. Amoran OE. Predictors of disclosure of sero-status to sexual partners among people living with HIV/AIDS in Ogun State, Nigeria. Niger $\mathrm{J}$ Clin Pract. 2012;15(4):385-90.

35. Sullivan KM. Male self-disclosure of HIVpositive serostatus to sex partners: a review of the literature. J Assoc Nurses AIDS Care. 2005; 16(6):33-47.

36. Akani CI, Erhabor O. Rate, pattern and barriers of HIV serostatus disclosure in a resource-limited setting in the Niger Delta of Nigeria. Tropical Doctor. 2006;36 (2):87-9.

37. Mayfield AE, Rice E, Rotheram-Borus BM. HIV disclosure among adult living with HIV.AIDS care. 2008;20:20(1):80 92.

38. Parker RG, Parrott R. Patterns of selfdisclosure across social support networks: elderly, middle-aged and young adults. Int J Aging Hum Dev. 1995;41 (4):281-97.

39. Kangwende RA, Chirenda J, Mudyiradima RF. HIV status disclosure among people living with HIV/AIDS at FASO, Mutare, Zimbabwe. Cent Afr J Med. 2009;55(14):1-7.

40. Ssali SN, Atuyambe L, Tumwine C , Segujja E, Nekesa N, Nannungi . Reasons for disclosure of HIV status by people livimg with HIV/AIDS and in HIV care in Uganda: an exploratory study. AIDS Patient Care STDS. 2010;24(10):675-81.

41. Olagbuji BN, Ezeanochie MC, Agholor KN, Olagbuji YW, Ande AB, Okonofua FE. Spousal disclosure of HIV serostatus among women attending antenatal care in urban Nigeria. J Obstet Gynaecol. 2011;31(6):486-8.

42. Gari T, Habte D, Markos E. HIV positive status disclosure among women attending ART clinic at Hawassa University Referral 
Hospital, South Ethiopia. East Afr J Public Health. 2010;7(1):87-91.

43. Sullivan K, Voss J,Li D. Female disclosure of HIV-positive serostatus to sex partners: a two-city study. Women Health. 2010;50(6):506-26.

44. Deribe K, Woldemichael K, Njau BJ, Yakob B, Biadgilign S, Amberbir A. Gender differences regarding barriers and motivators of HIV status disclosure among HIV-positive service users. Journal of Social Aspects of HIV/AIDS. 2010;7(1):30-9.

45. Kairania R, Gray R, Kiwanuka N, Makumbi F, Sewankambo N. Disclosure of HIV results among discordant couples in Rakai, Uganda: A facilitated couple counseling approach. AIDS Care. 2010;22(9):1041-51.

46. Tadese AE, Benihun M, Mamo W. Predictors of HIV status disclosure to sexual partners among people living with HIV/AIDS in Ethiopia.

47. Issiaka S, Cartoux M, KY-Zebro O, Tiendrebeogo S, Meda N. Living with HIV: women's experience in Burkina Faso, West Africa. AIDS Care. 2001;13:123-8.

48. Ezegwui HU, Nwogu-Ikojo EE, Enwereji JO, Dim CC. HIV serostatus disclosure pattern among pregnant women in Enugu, Nigeria. J Biosos Sci. 2009;41(6):789-98.

49. Anglewicz P, chintsanya J. Disclosure of HIV status between spouses in rural Malawi. AIDS Care. 2011;23(8):9981005.

50. Bouillon K, Lert F, Sitta R, Schmaus A, Spire B, Dray-Spira R. Factors correlated with disclosure of HIV infection in the French: Antilles and French Guiana: results from the ANRS-EN13-VESPADFA Study. AIDS. 2007;21(1):89-94.

51. Ndiaye C, Boileau C, Zunzunegui MV, Koala S, Aboubacrine SA, Niamba P. Gender-related factors influencing HIV serostatus disclosure in patients receiving HAART in West Africa. World Health Popul. 2008;10(3):43-54.

52. Titilope AA, Adediran A, Umeh C, Akinbami A, Unigwe O, Akanmu AS. Psychosocial Impact of disclosure of HIV Serostatus in heterosexual relationship at the Lagos University teaching Hospital, Nigeria. Niger Med J. 2011;52:55-9.

53. Daniel OJ, Oladapo OT. Self-disclosure of HIV sero-status to sexual partner in Nigeria. Sexual Health Matters. 2004; 40:30-35.

54. Shacham E, Small E, Onen N, Stamm K, Overton ET. Serostatus disclosure among adults with HIV in the era of HIV therapy. AIDS Patient Care STDS. 2012; 26(1):2935.

55. King R, Katuntu D, Lifshay J, Packel L, Batamwita R, Nakayiwa S. Processes and outcomes of HIV serostatus disclosure to sexual partners among people living with HIV in Uganda. AIDS Behav. 2008;12(2):232-43.

56. Miller AN, Rubin DL. Motivations and methods for self-disclosure of HIV seropositivity in Nairobi, Kenya. Journal of AIDS Behav. 2007;11(5):687-97.

57. National Population Commission (NPC). NATIONAL CENSUS Nigeria2006.

58. Kirkwood BR, Steane JAC. Calculation of required sample size. In Essential medical statistics. 2nd Editio. Oxford Blackwell publishing company; 2006: 413-28.

59. Amy NM, Chopra SK. Factors related to HIV disclosure in 2 South African Communities. AmJ Public Health. 2007;97(10):1775-81.

60. Antelman G, Smith Fawzi MC, Kaaya S, Mbwambo J, Msamanga GI, Hunter DJ. Predictors of HIV-1 serostatus disclosure: a prospective study among HIV-infected pregnant women in Dar es Salaam, Tanzania. AIDS. 2001;15(14):1865-1874. 
61. Erah P, Arute J. Adherence of HIV/AIDS patients to antiretroviral therapy in a tertiary health facility in Benin City. African Journal of Pharmacy and Pharmacology. 2008;2(7):145-52.

62. Agu KA, Okojie O, Oqua D, King RC, Omonaiye $\mathrm{O}$, Onuoha $\mathrm{C}$, et al. Medication Adherence and Risk factors for Nonadherence among Patients taking Highly Active Antiretroviral Therapy West African Journal of Pharmacy 2011;22(1):19 - 26.

63. Da Silveira V, Drachler Mde L, Leite J, Pinheiro C. Characteristics of HIV antiretroviral regimen and treatment adherence. Brazilian Journal of Infectious Disease. 2003;7(3):194-201.

64. Iliyasu I, Kabir M, Abubakar I, Babashani M, Zubair Z. Complianceto antiretroviral therapy among AIDS patients in Amino Kano Teaching Hospital, Kano, Nigeria. Nigerian Journal of Medicine. 2005;14 (3):290-4.

65. Cauldbeck MB, O'Connor C, O'Connor MB, Saunders JA, Rao B, Mallesh VG, et al. Adherence to anti-retroviral therapy among HIV patients in Bangalore, India. AIDS Research and Therapy 2009;6(7):18.

66. Mansergh G, Marks G, Simoni JM. Selfdisclosure of HIV infection among men who vary in time since seropositive diagnosis and symptomatic status. AIDS. 1995;9(6):639-644.

67. Skogmar S, Shakely D, Lans M, Dannell JK, Andersson R, Tshandu N. Effect of antiretroviral treatment and counseling on disclosure of HIV serostatus in Johannesburg, South Africa. AIDS Care. 2006;18(17):725-730. 